\title{
Development of a Mobile GIS Property Mapping Application using Mobile Cloud Computing
}

\author{
Victor Neene \\ Department of Computer Science \\ University of Zambia \\ Lusaka, Zambia
}

\author{
Monde Kabemba \\ Department of Computer Science \\ University of Zambia \\ Lusaka, Zambia
}

\begin{abstract}
This study presents the development of a mobile GIS Property mapping application for use by local authorities in developing countries. Attempts to develop property mapping applications especially in developing countries have mostly used GIS desktop productivity software tools that required the digitization of property maps by highly skilled GIS experts. In addition, these applications lacked real time capture of attribute, spatial and image data of properties. A survey was conducted in the Kafue local authority to gather systems requirements for the mobile application. After design and modeling, the developed application was trialed in the field and 10 properties were mapped successfully. The software tools used in this study included Android Studio, Leaflet mapping library, Apache2 web server, PostgresSQL with PostGIS Extensions and OpenstreetMaps and MapBox mobile cloud computing mapping services. The hardware tools used included a laptop computer and a mobile phone running android operating system. The study showed that mobile property mapping applications can be developed by tapping into the computing resources provided by mobile cloud computing. The benefits of this model include real time complete property data capture and the use of non GIS experts in mapping projects.
\end{abstract}

Keywords-Leaflet; MapBox; mobile cloud computing; OpenstreetMaps; property mapping

\section{INTRODUCTION}

Property mapping is very important because local authorities generate revenue from properties. The revenue that is generated is utilized on the provision of basic services, infrastructure development and maintenance of infrastructure within the jurisdiction of the local authority. Despite the benefits that would accrue to local authorities through the collection of property taxes, it still only makes a small contribution of 0.5 percent to the GDP in Sub-Saharan Africa compared to a contribution of 2 percent in the developed world [1]. The small contribution to the GDP in Sub-Saharan Africa is attributed to paper based property databases that local authorities maintain. These databases do not substantially help in the process of identification of properties because they do not have the required geographical information on the properties that are physically on the ground [2]. The property databases also in most cases do not have street names of the residential areas. This has resulted in the failure by the local Authorities to locate the properties for purposes of bill delivery either physically or through the public postal office system. In addition, follow-ups to residents that have defaulted on tax payments have proved to be a very daunting task [3]. The other challenge pertains to the update of the maps that show the geographical locations of the properties that are captured in the property databases. This problem has been exacerbated by the high number of properties that are being developed [4].

In this study, we develop a field based mobile GIS property mapping application to help the local authorities overcome challenges of property identification and capture. We begin by first reviewing the literature on the existing technologies and the related applications that have been developed. We then proceed to discuss the materials and methodology used in the study after which we describe how the application works. A discussion on the design and modeling then follows. We then compare our application with related applications before we discuss the work and then conclude.

\section{LITERATURE REVIEW}

\section{A. Mobile Cloud Computing}

Applications developed for mobile devices are increasingly becoming abundant because mobile computing has provided tools to users for utilization wherever they are and whenever they want to use them irrespective of their geographical position [5]. Examples of applications that have emerged include m-commerce, m-learning, m-healthcare, mtravelling and m-GIS applications [6]. This mobility has created a resource constraint for mobile devices because they were designed with limited computing, storage and energy resources [7]. The solution to this problem has been provided by mobile cloud computing technology which is an amalgamation of mobile computing and cloud computing. Cloud computing depends on the sharing of network resources to attain a high availability of computing resources and it helps in reducing management and economic costs. It is facilitated by hardware virtualization technology, parallel computing, distributed computing and web services [8]. Applications are delivered as services on the internet and are provided by shared hardware and software systems in very large data centers. This model ensures that computing resources are offloaded from the mobile device and are in turn provided as pay as you go and on demand services [5].

\section{B. Leaflet, GeoJSON and OpenStreetMaps}

The Leaflet mapping Library and GeoJSON objects are some of the tools that can be used to build mobile GIS Cloud Computing applications. The Leaflet Mapping Library is an 
opensource JavaScript Mapping Library that is used for mobile friendly interactive maps. It has a very small JavaScript code footprint of only $38 \mathrm{~Kb}$ and it has most of the mapping features that developers require for use in their mobile mapping application projects. It works on almost all the existing desktop and mobile platforms and it is scalable through the use of plugins. It is also used for rendering vector and raster maps such as OpenStreetMaps and MapBox respectively [9]. GeoJSON objects are geographical data formats coded in JavaScript Object Notation (JSON) that are used for encoding different geographic data structures. The geographic structures include point, polygon, multipoint, multistring and multipolygon geometries [10]. OpenStreetMaps are free vector maps that are being constructed by mapping volunteers around the globe. The OpenstreetMap (OSM) project was started because geographical data is not provided for free in many parts of the world. The affordable GPS units embedded in mobile devices have facilitated the voluntary creation of free vector maps by mapping volunteers around the world [11]. OSM is sometimes referred to as the Wikipedia of maps because the project facilities distributed work around a common product (maps). Its database contains geographic data for many parts of the world. Its website has a set of software tools that enables registered users to contribute to, download, or otherwise interact with the spatial database [12]. The most common method used to record spatial data is through a GPS receiver and the spatial data is later edited using the freely available editors. Additional information about the collected spatial data is added by supplying attribute data and storing the final data set in the OSM database [13].

\section{Related Works}

In the USA, Rutgers University developed an offline vacant property mapping application that used a smartphone running ArcGIS collector as the front end and ArcGIS desktop as the backend. The backend and the frontend were linked using ArcGIS online (AGOL) that provided the map data. Primary attribute and spatial data was collected offline and later synchronized because of budget limitations [14]. In Ghana, Martey and Tagoe developed a GIS based Property Information System (GPTIS). GPTIS was developed to help in the administration of Property Tax through the use of a digital Map that showed the properties in the Municipality. It was developed for Tarkwa Nsuaem Municipal Assembly (TNMA). GPTIS was programmed using the .NET development framework and Visual Basic was used as the programming Language. The Map Object Library developed by the Environmental Systems Research Institute Inc(ESRI) was used to provide Mapping functions. MapBox Earth API's were also used. The Backend for data storage used shape data files, image files and Microsoft Access Database. GPTIS interface allowed users to perform spatial and non-spatial queries, update of newly registered properties, update and processing of property attribute data. Spatial data was obtained by digitizing the Map of the study area and GIS software was used to geo-reference the Map. Non Spatial Attribute Data was entered through the user interface. GPTIS was designed as a standalone application with limited remote access features [15].
In Nigeria Oluwadare and Ojo used GIS in Olorunda Local Government Authority to determine the geographical location of each property with the associated property attribute data to help in the effective collection of tenement rates (property taxes). Spatial data was collected using a GPS receiver device on 85 parcels of land in Orolanda Local Government Authority. Satellite imagery of the area was downloaded from MapBox Earth software application. The Satellite image was then digitized into vector Maps using Corel Draw 11 and ILWIS 3.0 environment for georeferencing software applications. The final digitized map layers were then exported to ArcView 3.2a software. Property attribute data and GPS co-ordinates were input in a Microsoft Access Database and then linked with ArcView GIS. The GPS dataset helped in determining the shape and size of the property land parcels [16]. In Oluyole local Government Area of Oyo state Nigeria, a land information system was developed to map properties. Spatial data was acquired through the digitization and geo-referencing of the hard copy layout plan of the area. Attribute data was obtained through a social survey on the ground. ArcGIS desktop GIS were used both as a front end and a backend [17].

In Sri Lanka, an Integrated Geographical Buffering System (IGBS) was developed by for use to value land parcels for the purposes of property Taxation in the Gampola region in Kandy District in the Central Province of Sri Lanka. A high resolution satellite image of the area was digitised using ArcView GIS Version 3.1. A hand held GPS Receiver Device (Geo Explora XT) was used to assign co-ordinates on the image of the location of interest. IGBS features included acquisition, storage and retrieval of valuation and taxation information about the land, compilation of complete tax records, graphical display of spatial data, analysis and processing of meaningful land valuation [18]. In Mexico, Bently federated GIS developed the Cancun Federated Geospatial Information System so that Property Tax Collection Revenues could be increased. Ariel Photography was used to capture the Image of Cancun Municipality. Mobile hand held GPS devices where used to capture GeoCoordinates, property attribute data and images of the property. The property spatial and attribute data was subsequently integrated into a single map desktop GIS. The GIS system allowed the update of property information, discovery of properties with new development, entering, recording and production of property tax records. The GIS database was centralized and was accessible by other departments within Cancun Municipality [19]. In China, a Service Oriented GIS based Web Application was developed by Yang et al. to provide information on land and the corresponding prices in Feng County in the Jiangsu Province of the People's Republic of China. The Latest city maps of Feng County were digitized using ArcGIS and later uploaded to a Server. SQL Server 2008 was used as the main Relational Database Management Systems and ArcSDE and ADO.NET were used as communication tools between the business logic tier and data tier. This was done to facilitate management of spatial and attribute data in SQL Server 2008. ArcGIS server was used to display, query and analyze land prices. The features of the GIS based Web Application included, map frame for viewing of spatial land price Information, Zoom 
in/out, map printing, document download, upload of new data sets of spatial and attribute data [20].

\section{MATERIALS}

The materials used in this study included hardware and software tools. The hardware included an Asus Laptop Computer and a Huawei G630 mobile phone. The software included Android Studio 1.3.2, PostgresSQL version 9.3 with PostGIS extensions, Apache2 version 2.4.7, the Leaflet Mapping Library version 0.7.7, jquery and OpenStreetMaps and MapBox mobile cloud computing services. Table 1 gives the specifications of the hardware tools that were used in the study.

TABLE I. HARDWARE TOOLS SPECIFICATIONS

\begin{tabular}{|c|c|}
\hline Hardware & Specifications \\
\hline Asus Laptop & $\begin{array}{ll}- & \text { 1TB HDD } \\
\text { - } & \text { 5th gen Intel Core i5 processor } 2.2 \mathrm{GHz} \text { with Burst Frequency up to } 2.7 \mathrm{GHz} \\
- & 8 \mathrm{~GB} \text { of RAM clocked at } 1,600 \mathrm{MHz} \\
- & \text { 2GB Nvidia GeForce } 920 \mathrm{M} \\
- & 366 \times 768 \text { pixel resolution } \\
- & 64 \text { bit Operating System }\end{array}$ \\
\hline Huawei G630 Mobile Phone & $\begin{array}{ll}\text { - } & \text { GSM/HSPA Network } \\
\text { - } & 720 \text { x } 1280 \text { pixels ( } 294 \text { ppi pixel density) } \\
\text { - } & \text { Quad-core } 1.2 \mathrm{GHz} \text { Cortex-A7 } \\
\text { - } & \text { Camera - Geo-tagging, } 8 \text { MP Back, } 1 \mathrm{MP} \text { front, autofocus, LED flash } \\
\text { - } & \text { GPS with A-GPS } \\
\text { - } & \text { Android } 4.3 \\
& \text { microSD, up to } 32 \mathrm{~GB} \text { (dedicated slot) }\end{array}$ \\
\hline
\end{tabular}

\section{METHODOLOGY}

The study used the agile software development methodology. The mobile application system requirements for the study were formulated from the survey that was conducted at Kafue local authority and from secondary sources in the literature. The survey used questionnaires and interviews to inform the design of the mobile mapping application. Before the property mapping commenced, the trial mapping area was mapped by using the embedded GPS unit of the mobile phone and OpenStreetMap mapping tools to include roads and points of interest. More than five days later, the changes become visible on the global OpenStreetMap vector maps. The mapping of roads facilitated the smooth mapping of property land parcels. The developed mobile application was trialed in the Parkview Estates of Kafue local authority. The attribute, spatial and image data was captured in real time on the ground from residents after consent was obtained to have their properties mapped. The property data was stored on the laptop computer. Ten properties were successfully mapped. Spatial data was obtained using a combination of MapBox raster maps and the Mobile Device's GPS unit in conjunction with OpenStreetMaps vector maps from the mobile cloud computing services. The mobile device's Internet speed and the saving of the property attribute, spatial and image data on the laptop using the phone's WIFI $(802.11 \mathrm{~b} / \mathrm{g} / \mathrm{n})$ did not manifest any adverse latency during the mapping sessions. The latency was less than 100 milliseconds ( 0.10 seconds) on average.

\section{OPERATION AND USE OF THE MOBILE GIS PROPERTY MAPPING APPLICATION}

This section describes how the implemented mobile GIS application is operated and used. The first task in the property mapping process involves the capture of the property attribute data which includes the capture of owner, land and property details. The second task involves the capture of spatial data and property image data.

\section{A. How to Capture Attribute Data}

Property attribute data capture is carried out in three stages using three different screens. The first screen that is used is shown in Fig. 1. This screen captures details that pertain to the property owner. Validation checks are performed to ensure that data is entered correctly and that all mandatory fields are not left blank. When the create button is clicked the property owner record is saved in the PostgresSQL database and a unique owner identity number is generated.

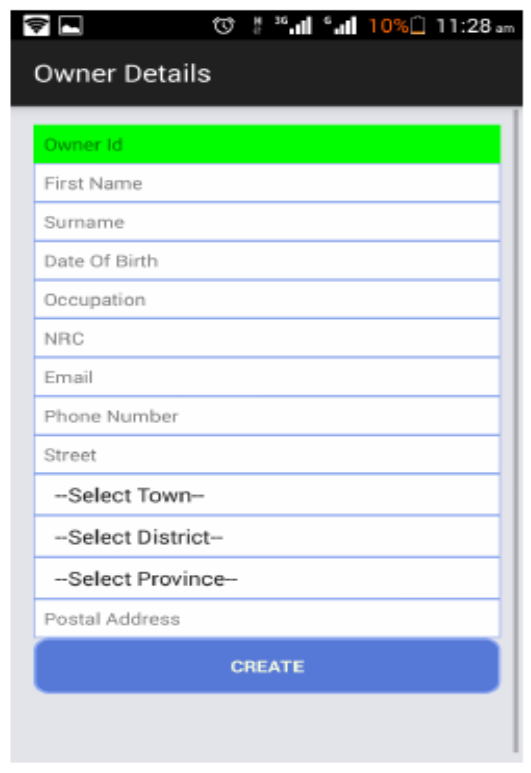

Fig. 1. Property owner details capture screen. 
Fig. 2 shows the screen that is used to capture land attribute data. When a valid Owner Identity Number is entered and focus moves to the next field, property owner names and national registration card number (NRC) are retrieved. The rest of the fields from the land use type to ward require the user to fill them manually. As data is entered in the fields, appropriate validation and mandatory checks are done. When the create button is clicked, the land record is created and a unique land identity number is generated.

Fig. 3 shows the property details screen that is used to capture property (building) attribute data. When a valid owner identity number is entered in the owner id field, details from the owner record and from the associated land record are retrieved. Property Descriptions, year constructed and building use data fields are entered manually by the user. As the data fields are filled, validation and mandatory field checks are done.

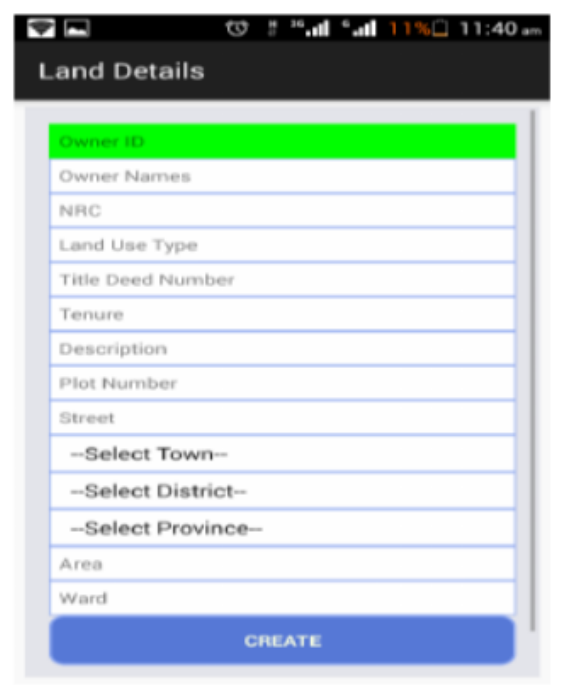

Fig. 2. Land details capture screen.

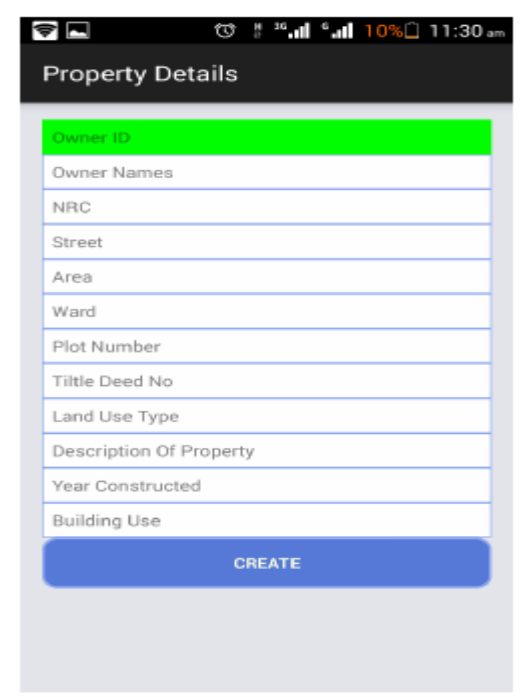

Fig. 3. Property details capture screen.

\section{B. How to Capture Spatial and Image Data}

Fig. 4 and 5 shows the first and second tabs of the property mapping screens, respectively. The first tab is used to retrieve owner property details as shown. The second tab is used to select the property mapping mode and also to capture images of the property.

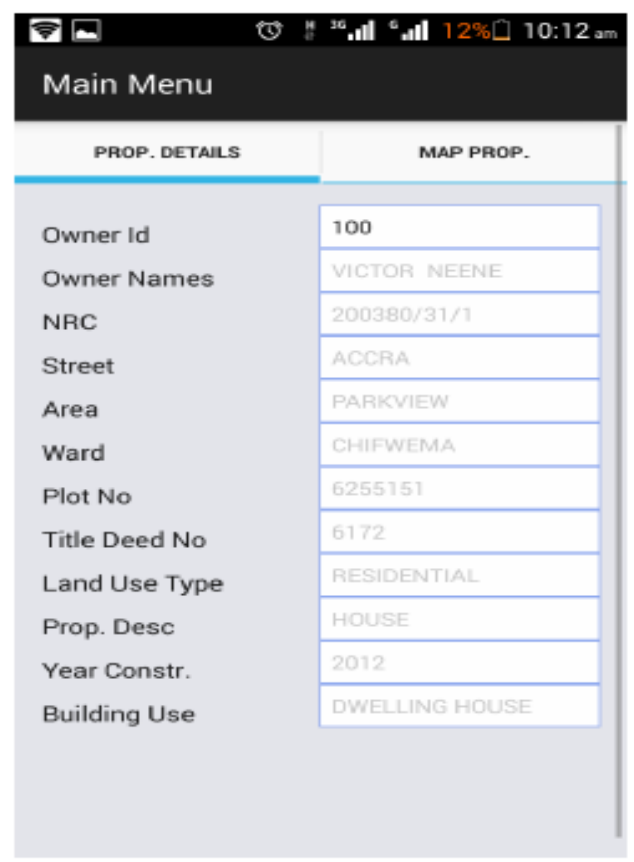

Fig. 4. First tab

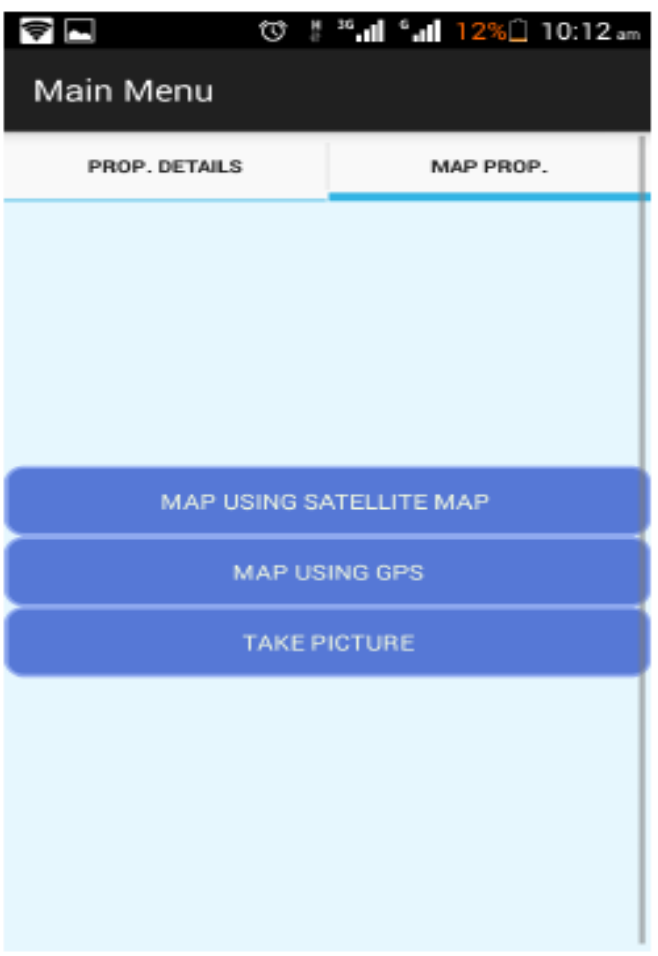

Fig. 5. Second tab. 
Fig. 6 shows the MapBox satellite image of the property mapping area when the Map Using Satellite Map option is selected. The mapper zooms in on the property using the (+) zoom icon. When the property is located, the mapper uses the line tool bar to draw the land parcel as shown. When the Finish menu item is clicked, the GPS coordinates represented by the white squares are then saved to the database and an appropriate message is displayed.

Fig. 7 shows the screen for the Map Using GPS option. The GPS Blue Marker, shown is displayed for ten seconds. As the mapper moves around, the marker also moves. When the approximate visual position of the GPS marker is on an approximate beacon location as guided by the underlying OpenStreetMap roads, a white square is placed on top of the marker to capture the GPS coordinates. This process is repeated for all the beacons. When the finish menu item is clicked, the GPS coordinates represented by the white squares are then saved to the database and an appropriate message is displayed.

The take picture function invokes the mobile device camera to enable the mapper take pictures of the property. A picture is transmitted to the webserver for storage immediately it is taken. The application allows the mapper to take as many pictures as possible.

\section{How to View Mapped Properties}

Fig. 8 and 9 shows the list of properties and an overview of land parcels respectively when captured during the property mapping Exercise.

Fig. 10 shows the Mapped Land Parcels and the Pictures of the Property when mapped. When the Land parcel is tapped on the map, details of the property are displayed as shown. Clicking on the view photos of the property link displays the pictures of the property that are captured during a mapping exercise as shown in Fig. 11.

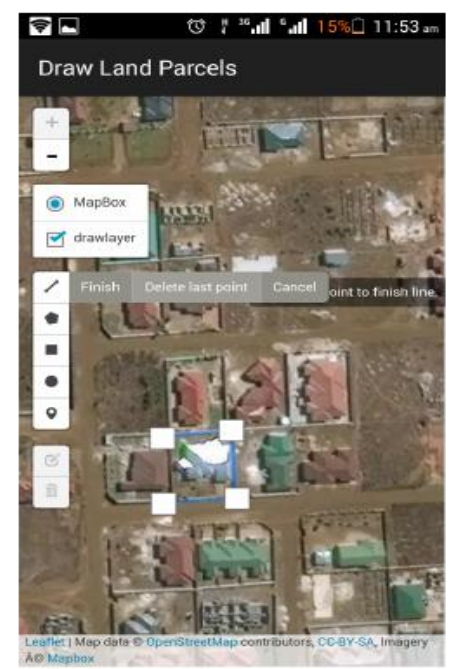

Fig. 6. Mapping using the MapBox Satellite Image.

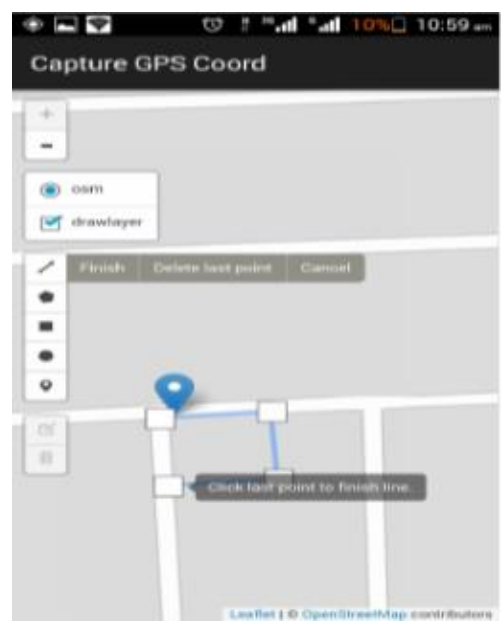

Fig. 7. Mapping using device GPS.

\section{(2) 0 令}

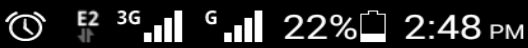

\section{Properties Mapped Btw Two Dates}

PROPERTIES MAPPED BETWEEN 2017-5-30 AND 2017-5-30

\begin{tabular}{|c|c|c|c|c|c|c|c|}
\hline LAND ID* & PLOT NUMBER & TITLE DEED NO. & OWNER ID & NRC & AREA & WARD & BUILDING USE \\
\hline 32 & 4854 & 5512 & 101 & 200280/11/1 & PARK VIEW ESTATES & CHIFWEMA & DWELLING HOUSE \\
\hline 35 & 9119 & 8828 & 104 & $187722 / 51 / 1$ & PARK VIEW ESTATES & CHIFWEMA & DWELLING HOUSE \\
\hline 33 & 6614 & 6126 & 102 & $306625 / 21 / 1$ & PARK VIEW ESTATES & CHIFWEMA & DWELLING HOUSE \\
\hline 31 & 6255 & 6172 & 100 & 200380/31/1 & PARK VIEW ESTATES & CHIFWEMA & DWELLING HOUSE \\
\hline 34 & 6626 & 6511 & 103 & $551255 / 51 / 1$ & PARK VIEW ESTATES & CHIFWEMA & DWELLING HOUSE \\
\hline 37 & 7255 & 2454 & 105 & $177267 / 51 / 1$ & PARK VIEW ESTATES & CHIFWEMA & DWELLING HOUSE \\
\hline 38 & 6179 & 6434 & 108 & $626268 / 31 / 1$ & PARKVIEW ESTATES & CHIFWEMA & DWELLING HOUSE \\
\hline 39 & 7161 & 9764 & 109 & $277766 / 31 / 1$ & PARKVIEW ESTATES & CHIFWEMA & DWELLING HOUSE \\
\hline 40 & 6172 & 9778 & 110 & $172736 / 54 / 1$ & PARKVIEW ESTATES & CHIFWEMA & DWELLING HOUSE \\
\hline 43 & 4643 & 2845 & 111 & $155527 / 36 / 1$ & PARKVIEW ESTATES & CHIFWEMA & DWELLING HOUSE \\
\hline
\end{tabular}

Fig. 8. Viewing mapped properties report. 


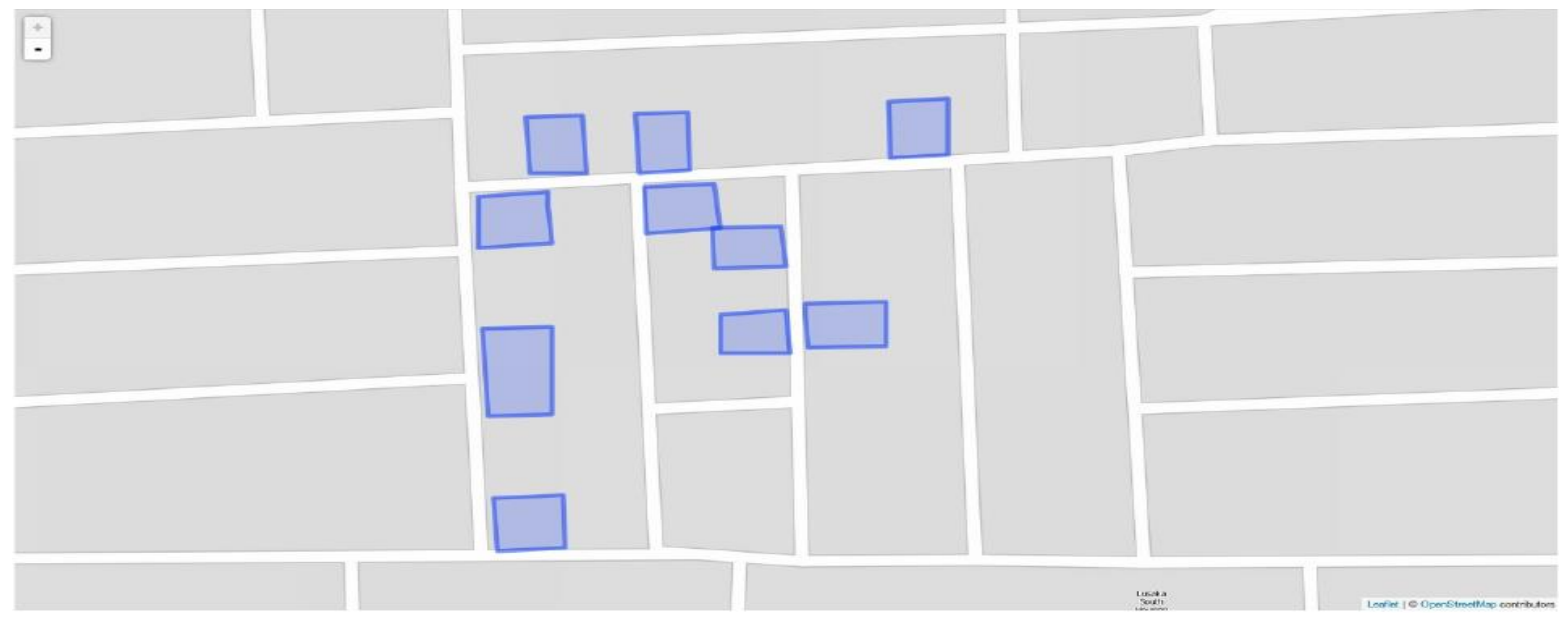

Fig. 9. Viewing mapped land parcels.

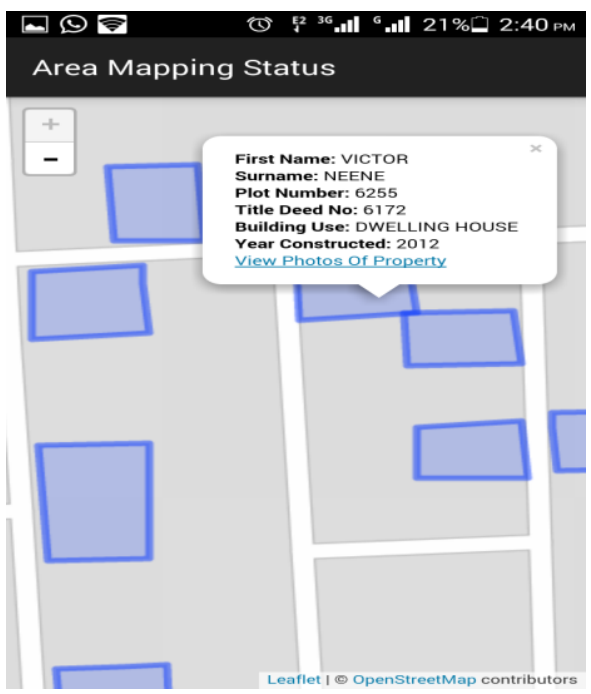

Fig. 10. Tapping mapped land parcels.

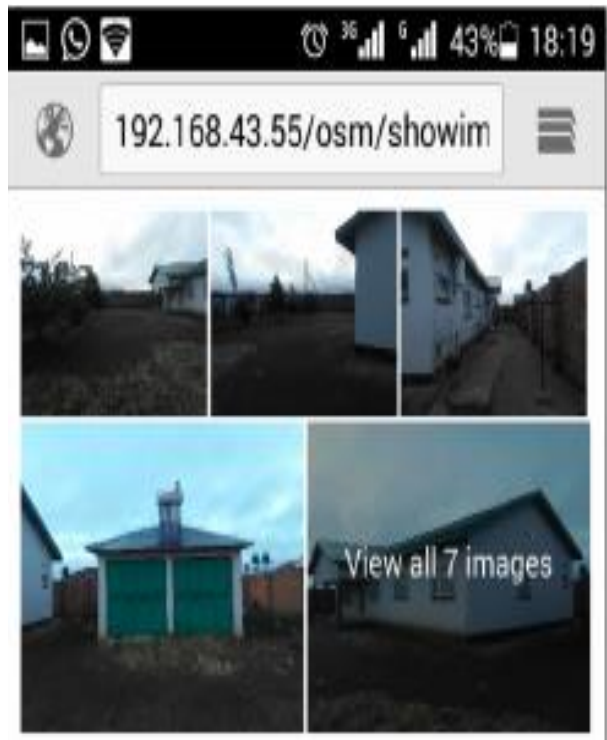

Fig. 11. Viewing property images.

\section{APPLICATION MODELLING}

This section presents the results of the final application modeling that was achieved after the several requirements formulation iterations.

\section{A. Entity Relationship Diagram(ERD)}

Fig. 12 shows the ERD of the application. The development of the ERD first started by identifying the entities from the business rules. There after the relationships between the entities were identified and the multiplicities and participation were also identified appropriately. There after primary and foreign keys for each entity were also identified. This was followed by the identification of other attributes for each entity. Lastly, the ERD was reviewed and revised by following the steps described until the final ERD was developed. The entities that were identified were the location, map, user, land, valuation, property, owner and individual. The ERD depicts the primary keys, foreign keys and attributes.

\section{B. Class Diagram}

Fig. 13 shows the classes that were developed to model the Application. The classes modeled the map, location, land, owner, property, valuation and individual entities in the property mapping problem. The relationships among the classes and methods of the classes are also shown. The map class can have one or many instances of the location class. It can also have one or many instances of the land class. The land class can have one or many instances of the property class. It can also have one instance of the location class. The property class can only have one instance of the valuation class. The owner class can have one or many instances of the property class. It can also have one or many instances of the location class. The individual class inherits from the owner class and re-implements the public functions.

\section{Mapping System Sequence Diagram}

Fig. 14 shows the System Sequence Diagrams (SSD) of the mapping spatial and image data. It depicts the exchange of messages between the mapper and the system. The user sends a message to the system to open the property mapping screen and the system responds by opening the screen. The user then sends a message with an owner id to the system and the 
system responds with the property details. A create map message is sent together with the captured GPS coordinates and the system responds with a confirmation message after successfully creating the map. The user then sends a save image message with an image and the system responds with a confirmation message after saving the image successfully.

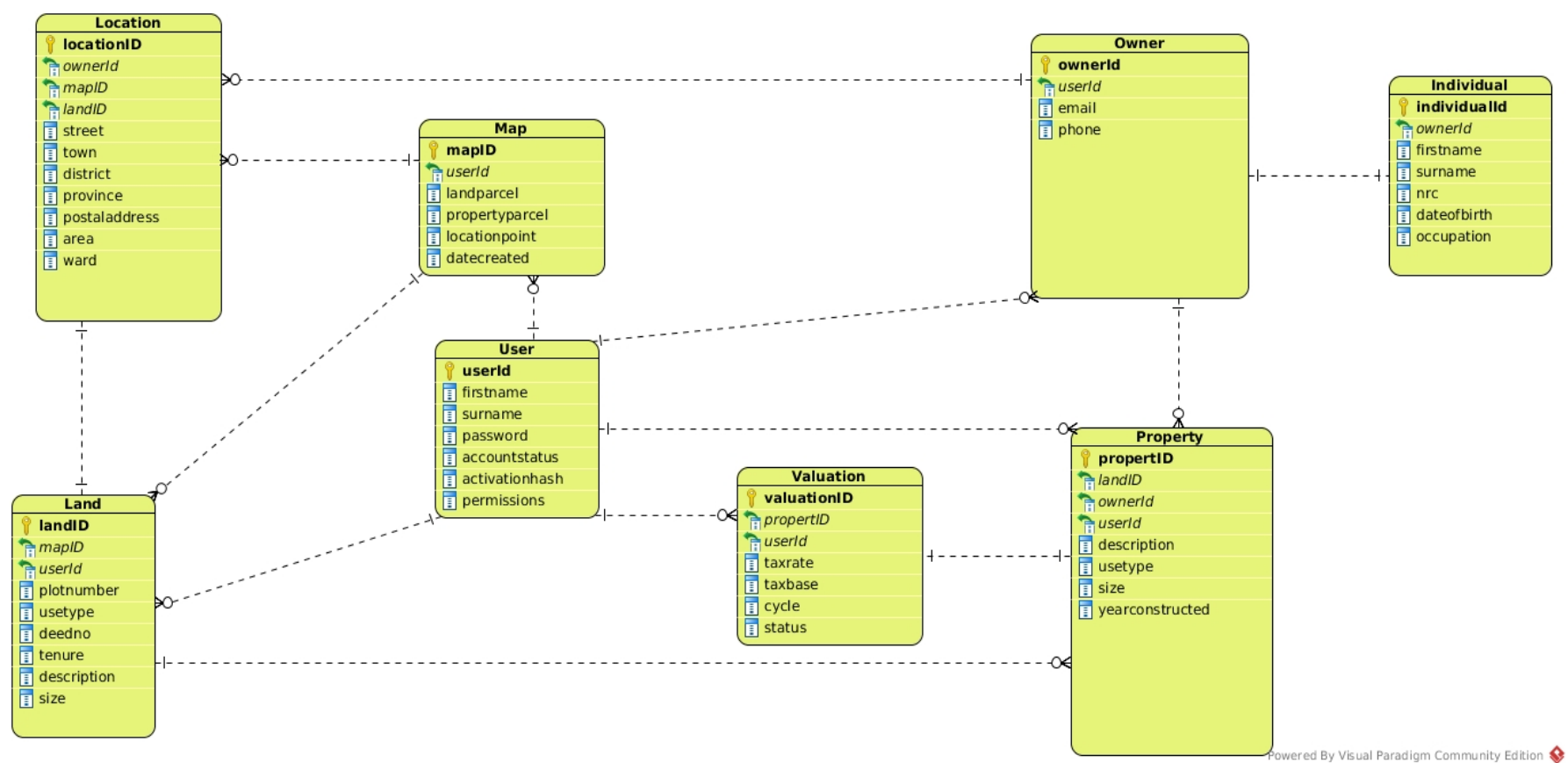

Fig. 12. ERD for the property mobile mapping application.

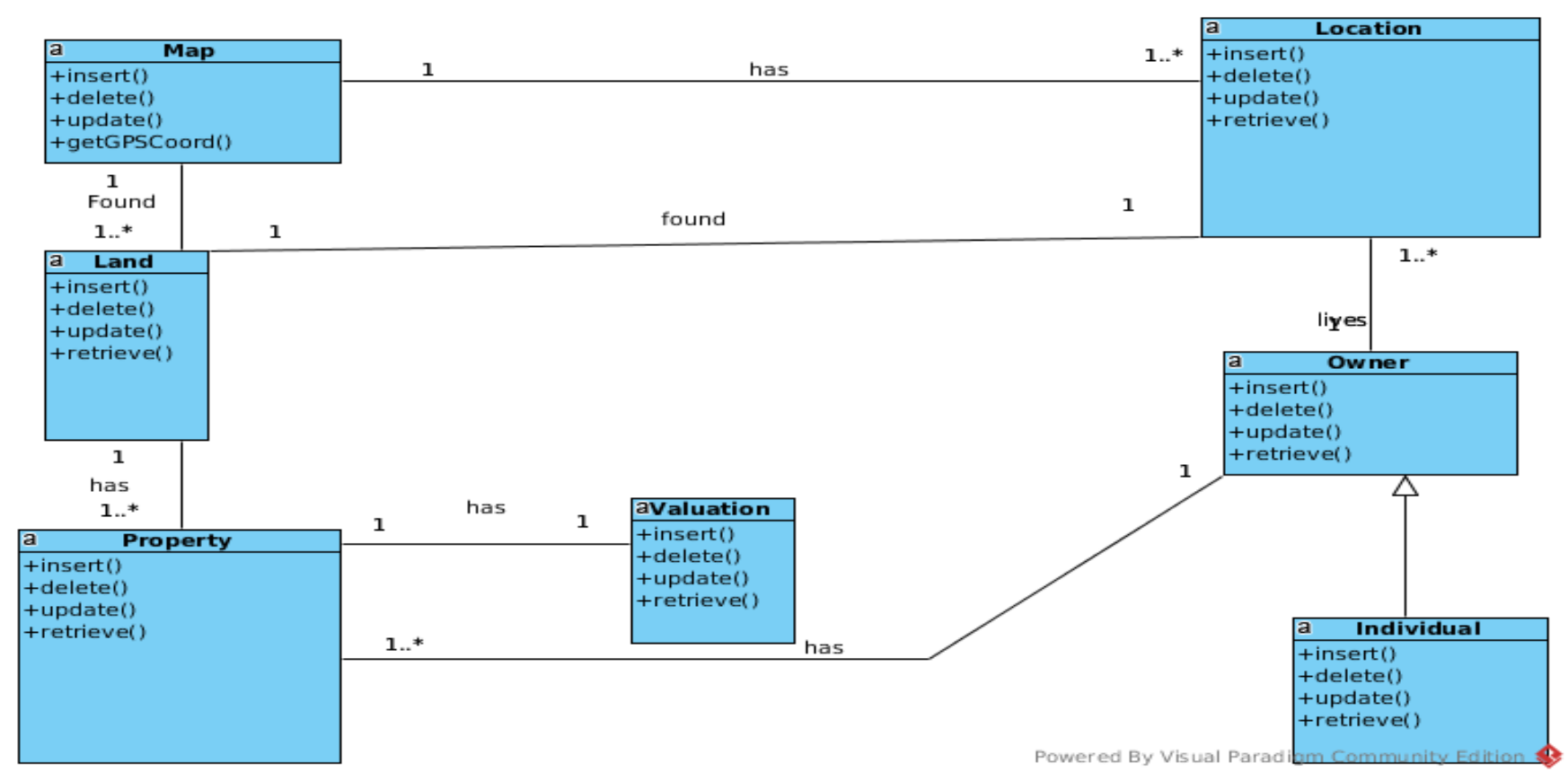

Fig. 13. Class diagram for the property mobile mapping application. 


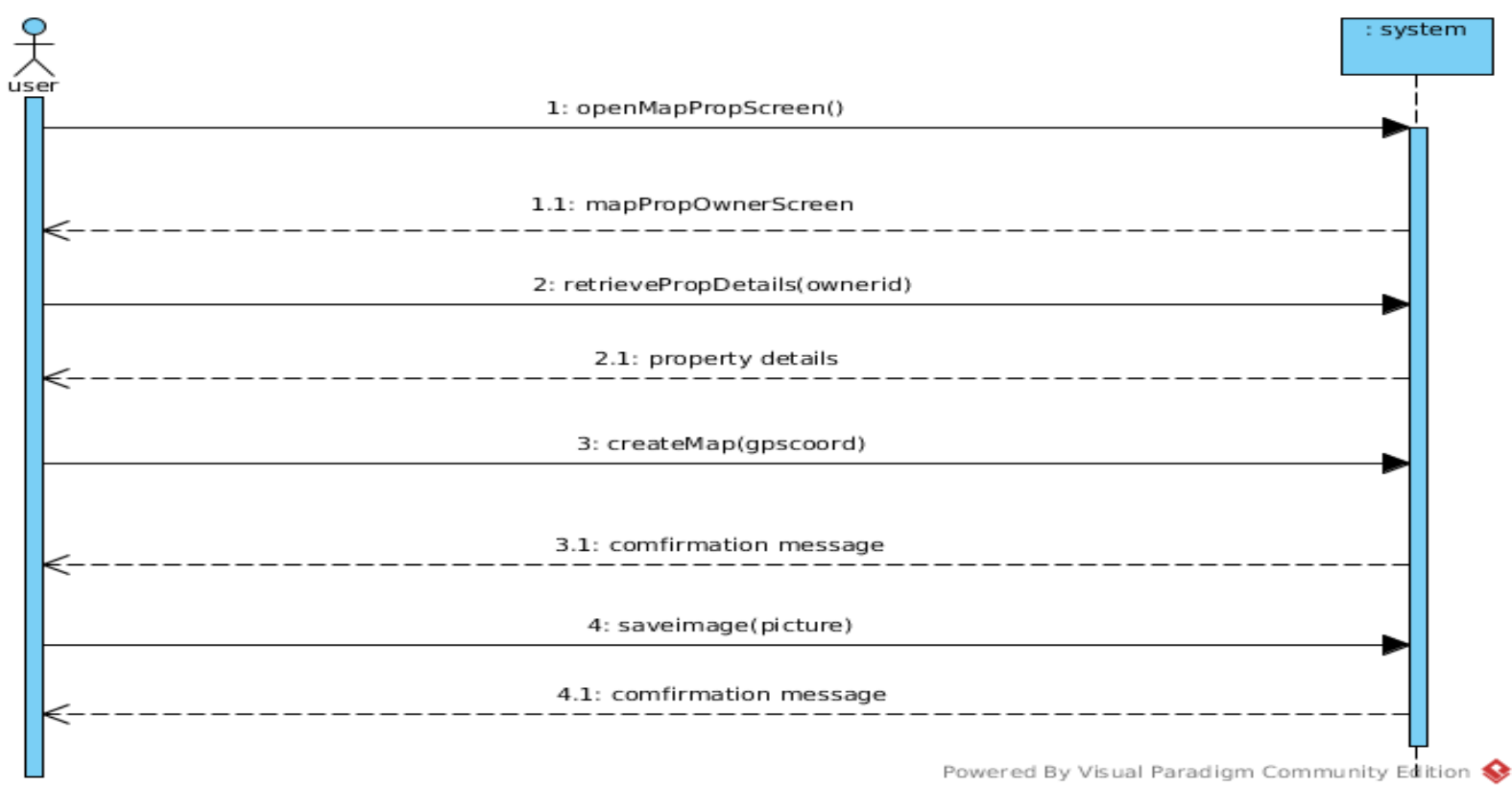

Fig. 14. System sequence diagram for the mapping spatial and image data mapping.
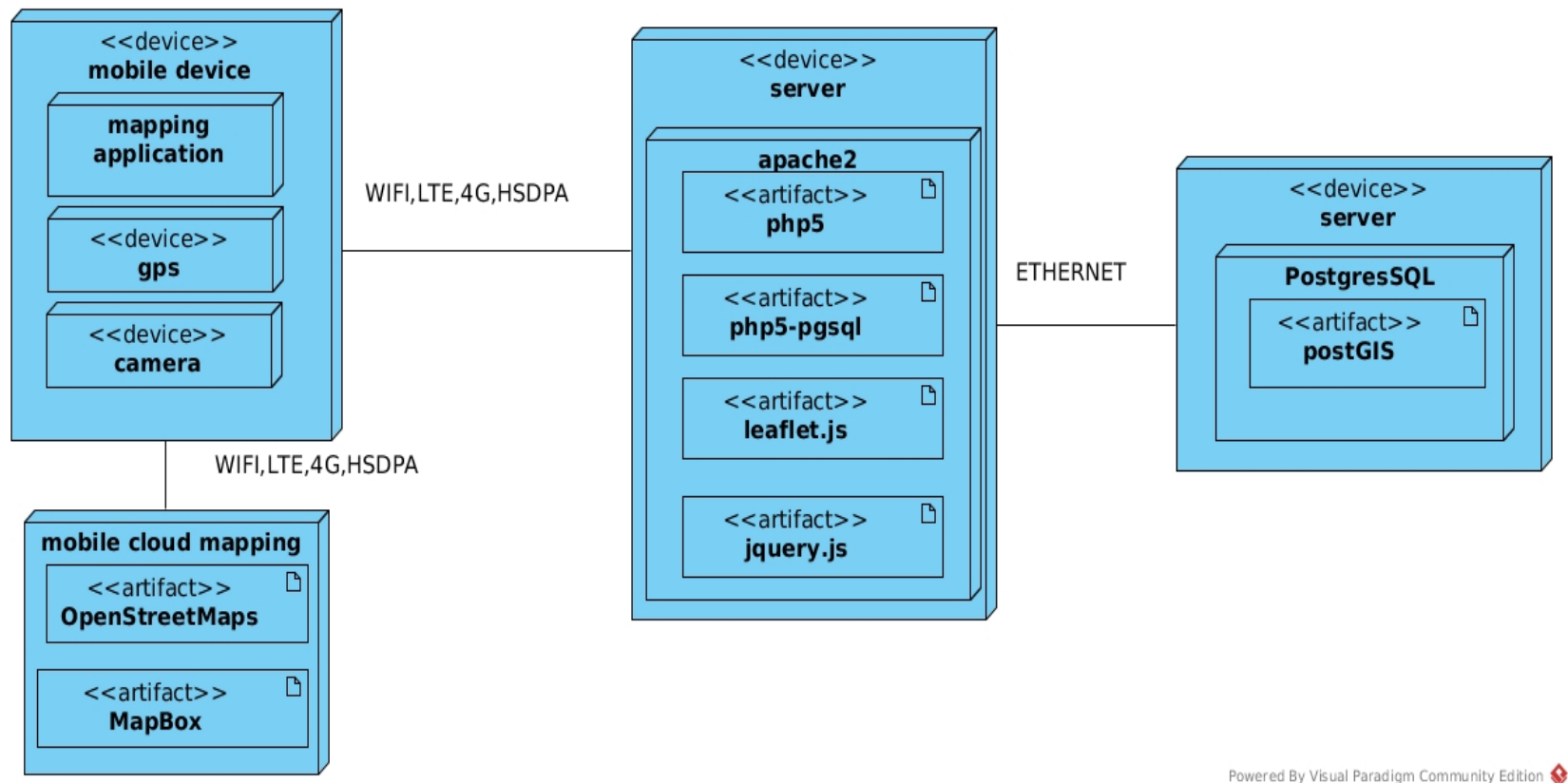

Fig. 15. Deployment diagram of the mobile application.

\section{SYSTEM ARCHITECTURAL DESIGN}

Pressman describes System Architecture as the manner in which the various parts of the software system are integrated to form a cohesive whole. The components can include a simple program module, object oriented classes, databases, middle ware, networks, clients and server hardware. System Architecture is important because it enables communication among stakeholders involved in the computer based system development. It also simplifies the model of how the system will be structured and how the components will work together
[21]. Fig. 15 depicts the Deployment Diagram of the mobile application. The following sections describe the components depicted:

\section{A. Mapping Application Component}

The mapping application component constitutes the frontend that runs natively on the mobile device. It uses the mobile device's GPS and camera hardware. It is interfaced with the Apache 2 web server and the mobile cloud mapping services. 


\section{B. Mobile Cloud Mapping Component}

This component is invoked by the Leaflet library mapping code that is loaded from the apache 2 webserver. The leaflet library in turn renders the OpenStreetMap vector and the MapBox raster maps provided by the mobile cloud computing services. The library also provides a map drawing tool plugin for capturing the property GPS Coordinates from the vector and raster maps.

\section{Apache2 Webserver Component}

The webserver component hosts the php business layer logic, JavaScript leaflet library and the jquery image display code that interfaces the mobile application (front end) and the PostgresSQL database (backend). The php5-pgsql API connects to the spatial database server. The php, leaflet and jquery code are invoked by the mapping application component during user interface interactions.

\section{PostgresSQL Spatial Database Server Component}

The database server component is made up PostgresSQL with PostGIS extensions Spatial relational database and it performs the role of the backend. The database is accessed by the php scripts residing on the Apache2 webserver component through the PostgresSQL php5-pgsql API. The API performs database manipulation and retrieval operations.

\section{E. Network Connectivity}

Network connectivity is provided by WIFI, LTE, 4G, HSDPA and Ethernet technologies to move data among the components.

\section{COMPARISON OF THE MOBILE GIS PROPERTY MAPPING APPLICATION WITH RELATED APPLICATIONS}

Our Mobile GIS property mapping application and the related applications described in the literature review section all have a component of capturing GPS coordinates either through a GPS Device or Geo-referencing a digitized map. However, some key differences pertaining to implementation exist.

The related applications require the digitization of maps of the area where properties are located. The maps are obtained either from primary or secondary sources. The process of digitization requires the use of desktop GIS productivity software. In contrast, our mobile GIS application uses existing digitized vector and raster maps of the property area provided by OpenStreetMaps and MapBox cloud computing mapping services respectively. Secondly, related applications capture data using a two stage approach. Spatial data is first captured in the office and then attribute and image data is later captured in the field. Thereafter, all the three data sets are then integrated as one. Our mobile GIS application, on the other hand, captures all the three data sets holistically in real-time in the field and in one session. Thirdly, related applications use Microsoft Access database, Microsoft SQL database or databases that are embedded in the GIS desktop productivity applications. In contrast, our mobile GIS application uses PostgresSQL with PostGIS extensions relational database that is designed specifically to store and process primitive geographic data types. Fourthly, related applications do not use the Leaflet mapping library that enables mobile mapping on mobile devices as compared to our mobile GIS application. Lastly, related applications do not use existing wireless technologies in their implementations; hence, they are devoid of mobility and full multiuser capabilities. In contrast, our mobile GIS application is fully mobile and multiuser.

\section{DISCUSSION}

The results of the mapping demonstrated that the application can be an efficient and useful tool in mapping of properties in the real time setting. The real time aspect has the advantage of capturing complete property data on the spot as residents will be available to provide the attribute data pertaining to their respective properties. Secondly, a good number of properties can also be captured over short periods of time and that would result in the clearance of property capture backlogs. Thirdly, on the local authority part, they can also hire and use non GIS experts in the mapping exercises because of the intuitive characteristics of the mobile mapping application user interface. Lastly, on the technological front, mobile computing, cloud computing and opensource software tools used in the development of the mobile GIS mapping applications have shown that it is possible to develop robust, user friendly and efficient mobile solutions. The cost of building mobile applications when these technologies and tools are used will be low because they can be used and obtained freely or at a very minimal cost.

\section{CONClusions}

In this study, the development of the mobile GIS property mapping application was presented. Affordable opensource development software tools and mobile cloud computing mapping services were used in the development and implementation of the mobile mapping application. A review of GIS based property mapping applications that were developed was conducted. The review showed that these applications lacked real time capture of complete property data and they used GIS desktop productivity software that required the skills of highly trained GIS experts. The study has shown that mobile GIS mapping applications can be developed by using mobile cloud computing services and opensource software tools. The mobile mapping application can help local authorities, especially in developing countries, in overcoming the challenges that they experience in property mapping.

\section{ACKNOWLEDEGMENT}

The authors would like to thank the staff at Kafue Local Authority and residents of Parkview Estates for the help rendered during the study.

\section{REFERENCES}

[1] N. Monkam and M. Moore, How Property Tax Would Benefit Africa. Africa Research Institute London, 2015.

[2] Y. Mohamed, Y. Mnguu, h. Mwatawala, and C. Mandara, “Assessment of property tax collection in informal settlements using geographical information system (gis) and remote sensing (rs) technology in temeke municipality: A case of keko ward, "2017. [Online]. Available: https://www.academia.edu/2549481/Assessment_of_property_tax_colle ction_on_informal_settlement_using_GIS_and_RS_in_Temeke_Munici pality_A_case_of_Keko_ward?auto=download. $\quad\left[\right.$ Accessed: $5^{\text {th }}$ September 2017]. 
[3] O.H. Fjeldstad and K. Heggstad, "Local government revenue mobilization in anglophone africa," 2012.

[4] J. Nieminen, "Property tax based revenue collection gis in the developing cities a new approach for sustainable urban development," WIT Transactions on Ecology and the Environment, vol. 54, 2002.

[5] N. Fernando, S. W. Loke, and W. Rahayu, "Mobile cloud computing: A survey," Future generation computer systems, vol. 29, no. 1, pp. 84106, 2013.

[6] M. M. Elwakil, R. F. Ibrahim, and H. A. Hefny, "New architecture for mobile gis cloud computing," New Architecture, vol. 4, no. 10, 2015.

[7] P. Bahl, R. Y. Han, L. E. Li, and M. Satyanarayanan, "Advancing the state of mobile cloud computing," in Proceedings of the third ACM workshop on Mobile cloud computing and services, pp. 21-28, ACM, 2012.

[8] Y. Jararweh, F. Ababneh, A. Khreishah, F. Dosari, et al., "Scalable cloudlet-based mobile computing model," Procedia Computer Science, vol. 34, pp. 434-441, 2014.

[9] R. G. Donohue, C. M. Sack, and R. E. Roth, “Time series no. 76, pp. 43-66, 2014.

[10] H. Butler, M. Daly, A. Doyle, S. Gillies, T. Schaub, and C. Schmidt, "Geojson," Electronic. URL: http://geojson. org, 2014.

[11] O. Website, “About openstreetmaps", 2017. [Online]. Available http://wiki.openstreetmap.org/wiki/About [Accessed: $15^{\text {th }}$ June 2017].

[12] R. Soden and L. Palen, "From crowdsourced mapping to community mapping: The post-earthquake work of openstreetmap haiti," in COOP 2014 Proceedings of the 11th International Conference on the Design of Cooperative Systems, 27-30 May 2014, Nice (France), pp. 311-326, Springer,2014.

[13] P. Neis and A. Zipf, "Analyzing the contributor activity of a volunteered geographic information project - the case of openstreetmap," ISPRS International Journal of Geo-Information, vol. 1, no. 2, pp. 146-165, 2012.
[14] L. Drake, B. Ravit, and L. Lawson, "Developing a vacant property inventory through productive partnerships: A university, ngo, and municipal planning collaboration in trenton, new jersey," Cities and the Environment (CATE), vol. 8, no. 2, p. 6, 2015.

[15] S. Martey and N. Tagoe, "Geo-property tax information system a case study of the tarkwa nsuaem municipality, ghana," Paper of FIG Working Week, 2012.

[16] C. O. Oluwadare and O. Ojo, "Database creation for tenement rate collection: The role of gis," The Pacific Journal of Science and Technology, vol. 15, no. 1, pp. 190-199, 2014.

[17] J. Igbokwe, J. Ojiako, A. Ekebuike, M. Adeleke, and E. Igbokwe, "Creation of cadastral information system for part of oluyole lga oyo state, nigeria," International Journal of Civil, Mechanical and Energy Science, vol. 2, 2016.

[18] R. S. Thilakarathnea, J. Gunatilakeb, and J. Jayakodya, "Integrated geographical buffering system for land taxation in sri lanka," The International Archives of the Photogrammetry, Remote Sensing and Spatial Information Sciences, Vol. XXXVII. Part B4, Beijing 2008.

[19] Bently, "Bently federated gis based on bently map enables cancun to collect 66 percent more property tax," 2017.[Online]. Available: http://www.bently/com/ /as-set/14/37/.ashx.[Accessed 20 $20^{\text {th }}$ January 2017].

[20] Y. Yang, Y. Sun, S. Li, S. Zhang, K. Wang, H. Hou, and S. Xu, "A gisbased web approach for serving land price information," ISPRS International Journal of Geo-Information, vol. 4, no. 4, pp. 2078-2093, 2015.

[21] R. S. Pressman, Software engineering: a practitioner's approach. Palgrave Macmillan, 2005. 